\title{
Successful Treatment of MMP-9-Expressing Angiosarcoma with Low-Dose Docetaxel and Bisphosphonate
}

\author{
Masaya Ishibashi Taku Fujimura Akira Hashimoto \\ Takahiro Haga Kaoru Onami Akira Tsukada \\ Yumi Kambayashi Takanori Hidaka Sadanori Furudate \\ Ryoko Shimada Setsuya Aiba
}

Department of Dermatology, Tohoku University Graduate School of Medicine, Sendai, Japan

\section{Key Words}

Angiosarcoma $\cdot$ MMP-9 $\cdot$ Bisphosphonate $\cdot$ Docetaxel

\begin{abstract}
We describe a 78-year-old Japanese patient with angiosarcoma on the scalp. Interestingly, immunohistochemical staining revealed this tumor as positive for matrix metalloproteinase 9 (MMP-9). After conventional therapy for angiosarcoma with surgical treatment and radiation therapy, we intravenously administered docetaxel at $40 \mathrm{mg} / \mathrm{m}^{2}$ body surface area together with oral administration of $17.5 \mathrm{mg}$ sodium risedronate hydrate. One and a half years after the standard treatment, there was no evidence of local recurrence or metastasis.
\end{abstract}

\section{Introduction}

Angiosarcoma is a rare vascular tumor most frequently found on the face and scalp. It behaves highly aggressive and spreads widely throughout the skin, recurs locally, and metastasizes early [1]. Standard treatment with resection and adjuvant radiotherapy results in local control in approximately $50 \%$ of patients at 1 year and median survival is approximately 8 months [1-3]. Therefore, further adjuvant or supportive therapy is necessary for the treatment of angiosarcoma.

Considerable evidence has implicated matrix metalloproteinases (MMP) in the degradation of the extracellular matrix (ECM) during the metastatic process [4]. Overexpression of MMP-9 has been demonstrated in human cancer. Murakami et al. [5] reported the expression of MMP-2 on subcutaneous angiosarcoma in canine. In human, 
MMP-1 expression was detected in splenic angiosarcoma [6]. However, there is no English report suggesting the expression of MMP-9 on human angiosarcoma of the skin. In this report, we describe a case of angiosarcoma in which complete remission was archived with low dose docetaxel and bisphosphonate after the standard treatment of angiosarcoma.

\section{Case Report}

A 78-year-old woman consulted us with a 6-month history of an asymptomatic nodule on her scalp. Her nodule has been surgically resected at a private clinic 3 months before her visit. Two weeks after the resection, skin nodules had suddenly enlarged. On her first visit, physical examination revealed a skin-colored nodule with a surgery scar, teleangiectasia and purpura on her scalp (fig, 1). The tumor size was $16 \mathrm{~mm}$ in diameter. Histologically, irregular anastomosing vascular channels lined by single layers of enlarged endothelial cells existed between collagen bundles with dense infiltration of lymphocytes ( fig. 2). Immunohistochemical staining revealed that these enlarged endothelial-like cells were strongly positive for CD31 and vimentin, and positive for Factor VIII and thrombomodulin, and negative for CD34, S-100, CK, SMA, and desmin. Moreover, these enlarged endothelial-like cells and tumor stromas were positive for MMP-9 (fig. 3 ) and negative for MMP-2 (data not shown). We used rabbit polyclonal anti-human MMP-9 antibody (Abcam, Tokyo, Japan) at a dilution of 1:100. In addition, we employed immunohistochemical staining for 9 cases of angiosarcomas that were histologically diagnosed in our institution, and about 78\% (7/9) cases of angiosarcomas were positive for MMP9. From these results, we diagnosed this patient as MMP-9-expressing angiosarcoma. Positron emission tomography (PET) scans showed no evidence of metastases. We resected the tumor with a 3-cm surgical margin. After surgical treatment, the patient was treated with radiotherapy (70 Gy). Then, we administered docetaxel monthly at $40 \mathrm{mg} / \mathrm{m}^{2}$ body surface area intravenously and weekly with oral administration of $17.5 \mathrm{mg}$ sodium risedronate hydrate. One and a half years after the surgical treatment, there was no evidence of local recurrence or metastasis.

\section{Discussion}

In our present case, we describe a case of MMP-9-expressing angiosarcoma treated with low-dose docetaxel and bisphosphonate. Like paclitaxel, docetaxel promotes microtubule assembly and inhibits the depolymerization of tubulin, thus stabilizing microtubules, but docetaxel has a higher potency $[4,7,8]$. However, in studies conducted in Europe, docetaxel monotherapy was rather ineffective for soft-tissue sarcoma, including angiosarcoma, and could not be recommended for further use [9]. Therefore, further supportive reagents are necessary for the treatment of angiosarcoma with docetaxel.

MMP-9 is a stromal factor that regulates the mobilization of hematopoietic stem cells from the bone marrow niche by solubilizing the membrane-bound form of c-KitL [10]. Because it remodels the extracellular matrix and promotes the sprouting and growth of new blood vessels by making VEGF available to the VEGFR-2/flk receptor on endothelial cells, MMP-9 is a linchpin in tumor progression [10]. Moreover, recently, several reports revealed the expression of MMP-9 on tumor correlated with the progression or prognosis of several skin tumors such as malignant melanoma, squamous cell carcinoma, basal cell carcinoma, and mycosis fungoides [11-14]. In addition, Koontz et al. [3] reported two cases of successful treatment of angiosarcoma with the administration of the anti-VEGF antibody bevacizumab along with radiotherapy prior to surgery. More recently, it was reported that pharmacological inhibition of MMP-9 by amino-bisphosphonate decreased pro-MMP-9 and VEGF in the 
serum and abrogated the induction of immunosuppressive macrophages, myeloidderived suppressor cells (MDSCs), in the tumor microenvironment $[15,16]$. In aggregate, inhibition of MMP-9 by bisphosphonate could be one of the optimal supportive therapies for the treatment of angiosarcoma by inhibiting tumor-induced angiogenesis and by the induction of anti-tumor immunity.

In conclusion, the combination of docetaxel with bisphosphonate was effective for MMP-9-expressing angiosarcoma and resulted in complete remission after the standard therapy for angiosarcoma. Further study is needed to confirm this limited observation.

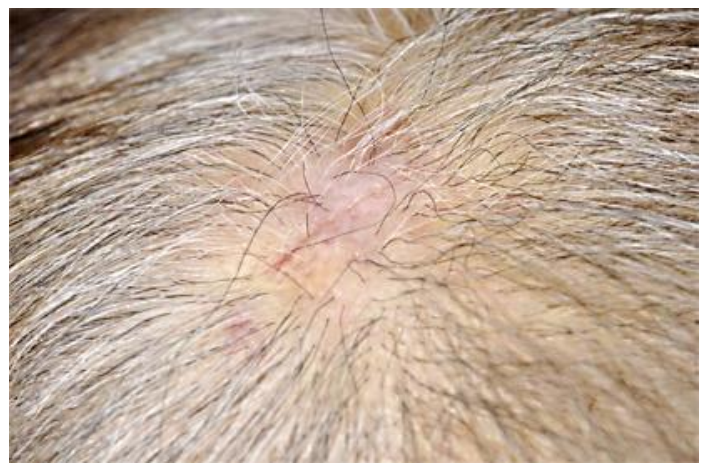

Fig. 1. A skin-colored nodule with surgery scar, teleangiectasia and purpura on the scalp.
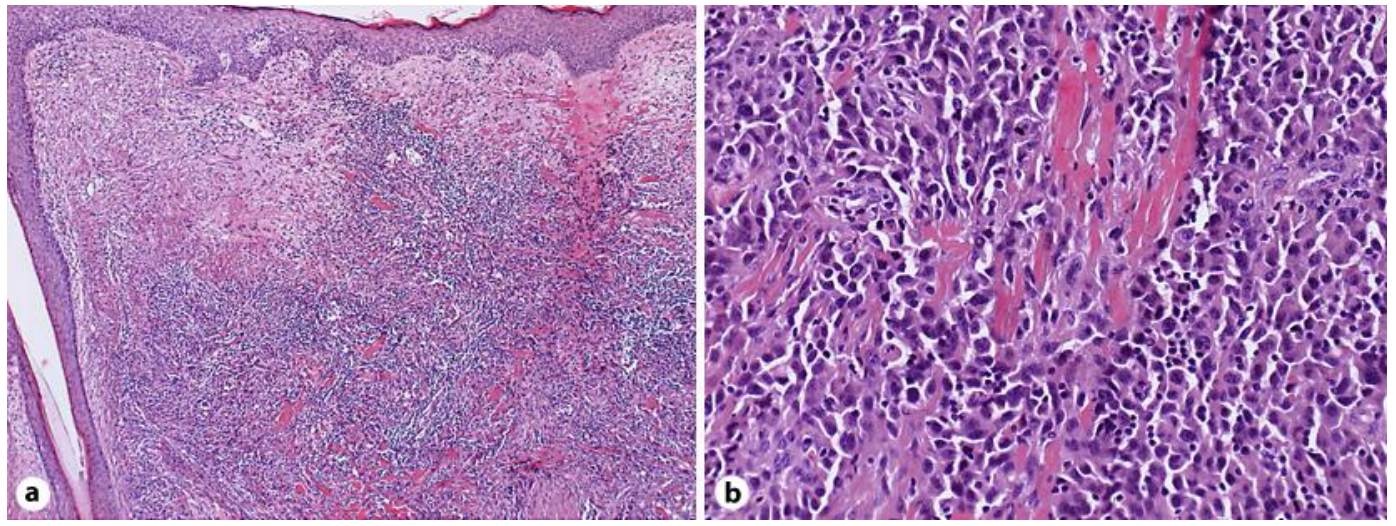

Fig. 2. Irregular anastomosing vascular channel lined by a single layer of enlarged endothelial cells between collagen bundles with dense infiltration of lymphocytes. $(\mathbf{a} \times 50 ; \mathbf{b} \times 200$; original magnification). 


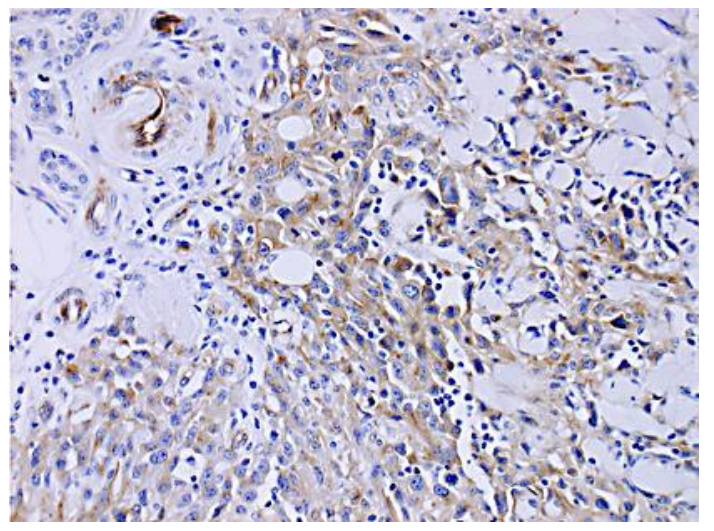

Fig. 3. Enlarged endothelial-like cells and tumor stromas were positive for MMP-9. $(\times 200$; original magnification).

\section{References}

1 Sasaki R, Soejima T, Kishi K, Imajo Y, Hirota S, Kamikonya N, Murakami M, Kawabe T, Ejima Y, Matsumoto A, Sugimura K: Angiosarcoma treated with radiotherapy: impact of tumor type and size on outcome. Int J Radiat Oncol Biol Phys 2002;15:1032-1040.

2 Ward JR, Feigenberg SJ, Mendenhall NP, Marcus RB, Mendenhall WM: Radiation therapy for angiosarcoma. Head Neck 2003;25:873-878.

-3 Koontz BF, Miles EF, Rubio MA, Madden JF, Fisher SR, Scher RI, Brizel DM: Preoperative radiotherapy and bevacizumab for angiosarcoma of the head and neck: two case studies. Head and Neck 2008;30:262-266.

4 Zucker S, Vacirca J: Role of matrix metalloproteinases (MMPs) in colorectal cancer. Cancer and Metastasis Rev 2004;23:101-117.

5 Murakami M, Sakai H, Kodama A, Yanai T, Mori T, Maruo K, Masegi T: Activation of matrix metalloproteinase (MMP)-2 by membrane type 1-MMP and abnormal immunolocalization of the basement membrane components laminin and type IV collagen in canine spontaneous hemangiosarcoma. Histol Histopathol 2009;24:437-446.

-6 Takeuchi T, Iwasaki S, Miyazaki J, Nozaki Y, Takahashi M, Ono M, Saibara T, Furihata M: Matrix metalloproteinase-1 expressing in splenic angiosarcoma metastasizing to serous membrane. Int J Clin Exp Pathol 2010;3:634-639.

-7 Nagano T, Yamada Y, Ikeda T, Kanki H, Kamo T, Nishiori C: Docetaxel: a therapeutic option in the treatment of cutaneous angiosarcoma. Cancer 2007;110:648-651.

8 Nagano T, Tai Y, Higashida Y, Fujiwara N, Oka M, Nishigori C: Docetaxel monotherapy for angiosarcoma in an elderly patient. Arch Dermatol 2007;43:1602-1603.

-9 Verweij J, Lee SM, Ruka W, Buesa J, Coleman R, van Hoessel R, Seynaeve C, di Paola ED, van Glabbeke M, Tonelli D, Judson IR: Randomized phase II study of docetaxel versus doxorubicin in first and second line chemotherapy for locally advanced or metastatic soft tissue sarcoma in adults. J Clin Oncol 2000;18:2081-2086.

10 Heissig B, Hattori K, Dias S, Friedrich M, Ferris B, Hackett NR, Crystal RG, Besmer P, Lyden D, Moore MA, Werb Z, Rafii S: Recruitment of stem and progenitor cells from the bone marrow niche requires MMP-9 mediated release of kit-ligand. Cell 2002;109:625-637.

11 Vihinen PP, Hernberg M, Vuoristo MS, Tyynelä K, Laukka M, Lundin J, Ivaska J, Pyrhönen S: A phase II trial of bevacizumab with dacarbazine and daily low-dose interferon-alpha2a as first line treatment in metastatic melanoma. Melanoma Res 2010;20:318-325.

12 Zhang G, Luo X, Sumithran E, Pua VS, Barnetson RS, Halliday GM, Khachigian LM: Squamous cell carcinoma growth in mice and in culture is regulated by c-Jun and its control of matrix metalloproteinase-2 and -9 expression. Oncogene 2006;25:7260-7266. 
13 Monhian N, Jewett BS, Baker SR, Varani J: Matrix metalloproteinase expression in normal skin associated with basal cell carcinoma and in distal skin from the same patients. Arch Facial Plast Surg 2005;7:238243.

14 Rasheed H, Tolba Fawzi MM, Abdel-Halim MR, Eissa AM, Mohammed Salem N, Mahfouz S: Immunohistochemical study of the expression of matrix metalloproteinase-9 in skin lesions of mycosis fungoides. Am J Dermatopathol 2010;32:162-169.

15 Melani C, Sangaletti S, Barazzetta FM, Werb Z, Colombo MP: Amino-biphosphonate-mediated MMP-9 inhibition breaks the tumor-bone marrow axis responsible for myeloid derived suppressor cell expansion and macrophage infiltration in tumor stroma. Cancer Res 2007;67:11438-11446.

16 Fujimura T, Mahnke K, Enk AH: Myeloid derived suppressor cells and their role in tolerance induction in cancer. J Dermatol Sci 2010;59:1-6. 